\title{
Withaferin A downregulates COX-2/NF-KB signaling and modulates MMP-2/9 in experimental endometriosis
}

\author{
Wang Dan ${ }^{1}$, Jiang Yiling ${ }^{2}$, Li Chun', Fan Jing ${ }^{1}$, Wang Huimin', Yang Xiaoxin ${ }^{1 *}$ \\ ${ }^{1}$ Department of Obstetrics and Gynecology, Wuhan Third Hospital-Tongren Hospital of WuHan University, Wuhan 430060, \\ ${ }^{2}$ Department of Obstetrics and Gynecology, Hubei Provincial Hospital of Integrated Chinese and Western Medicine, Wuhan \\ 430015, China
}

*For correspondence: Email: ValeryMagitt@yahoo.com; Tel/Fax: 0086-2788843447

\begin{abstract}
Purpose: To study the effect of withaferin A on an experimentally-induced endometriosis (EM) model. Methods: Female Sprague-Dawley rats were induced EM by implantation of autologous endometrium. Rats in the treatment group were administered withaferin A orally for 30 days. A separate group of rats that was administered gestrinone (GTN) served as positive control.

Results: Withaferin A treatment reduced the spherical volume of the ecto-uterine tissue was following five weeks after implantation. Histological analysis revealed regression of the lesions and restoration of normal architecture. Withaferin A effectively down-regulated the expressions and activities of matrix metalloproteinases (MMPs) 2 and 9 in the ectopic endometrium. The activities of MMPs-2 and 9 significantly $(p<0.05)$ decreased from 1.79- and 1.65-fold to 1.08- and 1.1-fold, respectively. The EMinduced up-regulation of NF-KB/COX-2 signaling was down-regulated by withaferin $A$. The levels of Cox-2 decreased significantly $(p<0.05)$ from $198 \%$ in EM control rats to $122.7 \%$ in $150 \mathrm{mg}$ withaferin A treated EM-induced rats. The increased levels of major inflammatory mediators nitric oxide (NO), TNF- $\alpha$, Interleukins (IL) - IL-1 $\beta$ and IL-6, markedly $(p<0.05)$ were reduced by withaferin A treatment, when compared to EM control group.

Conclusion: Withaferin A effectively suppresses the proliferation of lesions and modulates the immune responses-associated expressions of COX-2, NF-KB and matrix metalloproteinases (MMPs), viz, MMP2 and MMP-9
\end{abstract}

Keywords: Endometriosis, Inflammation, Matrix metalloproteinases, Nuclear factor-kB signaling, Withaferin A

\begin{abstract}
This is an Open Access article that uses a fund-ing model which does not charge readers or their institutions for access and distributed under the terms of the Creative Commons Attribution License (http://creativecommons.org/licenses/by/4.0) and the Budapest Open Access Initiative (http://www.budapestopenaccessinitiative.org/read), which permit unrestricted use, distribution, and reproduction in any medium, provided the original work is properly credited.

Tropical Journal of Pharmaceutical Research is indexed by Science Citation Index (SciSearch), Scopus, International Pharmaceutical Abstract, Chemical Abstracts, Embase, Index Copernicus, EBSCO, African Index Medicus, JournalSeek, Journal Citation Reports/Science Edition, Directory of Open Access Journals (DOAJ), African Journal Online, Bioline International, Open-J-Gate and Pharmacy Abstracts
\end{abstract}

\section{INTRODUCTION}

Endometriosis (EM) affects about $10 \%$ of females of reproductive age, and $20-50 \%$ of women who have infertility problems and chronic pelvic pain [1]. EM is characterized by presence of endometrium consisting of stroma and glandular tissue outside the uterine cavity [2]. Endometriotic lesions are associated with disintegration of extracellular matrix (ECM), invasion of the peritoneum, and migration of endometrial stromal cells. Inflammatory responses and increased oxidative stress are well implicated in EM [3]. Hormonal therapy and 
surgery are the current treatment options for EM. Surgery is aimed at removing the ectopic foci so as to restore normal pelvic anatomy and increase the probability of pregnancy. Hormonal therapy involves the use of oral contraceptives, gonadotropin-releasing hormone agonists, and progestogens [4]. However, the effects of hormone therapy are short-lived and are associated with severe side effects such as osteoporosis and pre-mature menopausal symptoms [5]. Moreover, the degree of recurrence is high, with lesions reappearing in about 30 - $50 \%$ females within 3-5 years after surgery [6]. Therefore, it is important to develop novel and effective treatments that can minimize recurrence of EM.

A better understanding of the signaling pathways and molecular events associated with the initiation and progression of EM aids in the identification of effective therapeutic strategies. Matrix metalloproteinases (MMPs), the proteolytic enzymes [7] are critically involved in coordination and regulation of the physiological functioning of the endometrium. Studies have reported elevated MMPs 2, 3, 7, and 9 in EM [8] and suppression of which inhibited ectopic lesions from human endometrium in mice [9].

Cytokines, the major inflammatory mediators promote endometriotic cell survival and growth $[10,11]$. Nuclear factor $\mathrm{kB}(\mathrm{NF}-\mathrm{kB})$ is known to activate inflammatory cascades that lead to cytokine synthesis [12]. Endometriotic lesions also express high levels of cyclooxygenase-2 (COX2) [13]. Thus, compounds that regulate MMPs and COX-2/NF-kB signals will be of immense medical values in the treatment of endometriosis. Withaferin $A$, a steroidal lactone originally isolated from Withania somnifera, Indian Winter cherry, and other members of the Solanaceae family has been traditionally used in Unani and Ayurvedic formulations [14]. Withaferin $A$ is associated with numerous beneficial effects such as anti-angiogenic [15], anti-cancer [16] and anti-diabetic [17]. These extensive pharmacological properties make withaferin $A$, a potent candidate drug for various health conditions. In this research, the effect of withaferin A supplementation on an experimental endometriotic rat model was investigated.

\section{EXPERIMENTAL}

\section{Ethics approval}

The study design and methods followed in the current investigation were permitted by WuHan University Animal Care, and Use Committee (Ethical Approval No: TESSS/67899839), and the processes taken were strictly in line with the $\mathrm{NIH}$ Care Guidelines for the use of laboratory animals [18].

\section{Study animals}

Healthy female Sprague-Dawley rats $(n=84,8$ to 9 weeks old; $180-220 \mathrm{~g}$ ), obtained from the animal care facility of WuHan University, were labeled for investigation. They were retained under controlled 12-h light/12-h dark cycle and environmental conditions of $22 \pm 1{ }^{\circ} \mathrm{C}$ and $55-$ $60 \%$ relative humidity. The animals were provided clean drinking water and standard pelleted diet and were adapted to in-house environment for a week prior to commencement of the experiments [18].

\section{Reagents and antibodies}

Antibodies against proteins - Cyclooxygenase (COX)-2 and MMP-2, MMP-9 (Cell Signaling Technology Danvers, MA, USA) TNF- $\alpha$, NF-kB $p 65, \beta$-actin, IKBa, p-ІKBa, p-IKKß, IKK $\beta, p-$ $\mathrm{IKK \alpha}$, and IKKa, and secondary antibodies (horseradish peroxidase-labelled lgG) from Santa Cruz Biotechnology Texas, USA were used for expression studies. Levels of cytokines (TNF- $\alpha$, IL-1 $\beta$, and IL-6) were determined by ELISA using commercially available kits that were procured from Biolegend (San Diego, CA, USA). Nitrite/nitrate kit from Cayman Chemical (Ann Arbor, MI, USA) was used to determination of nitric oxide (NO). Buffers for protein expression studies were got from Beyotime Institute of Biotechnology (Beijing, China). Withaferin A (Sigma-Aldrich, St.Louis, MO, USA); fetal bovine serum (FBS) (Thermo Scientific, USA); 3-(4,5dimethylthiazol-2-yl)-2,5diphenyltetrazoliumbromide polyvinylidene difluoride (PVDF) membranes, enhanced chemiluminescence (ECL) kit (Invitrogen), and RPMI1640 medium (Gibco, Grand Island, NY, USA) were used in the study. All other reagents and chemicals that were used for analysis were purchased from Sigma-Aldrich, unless otherwise are mentioned.

\section{Study design and animal grouping}

Following the acclimatization period (7 days), the rats were separated to 6 treatment groups at random ( $n=12$ per group). The procedures used in experimental endometriosis were as previously reported by Vernon and Wilson [19]. The rats were anaesthetized (i/m, ketamine and xylazine), and a midline incision of $3-\mathrm{cm}$ was made in the abdominal region to access the uterus. One uterine horn was removed, and cut along the longitudinal axis and sectioned $(5 \times 5 \mathrm{~mm}$ 
fragments). The uterine sections were then carefully implanted into the peritoneum and sutured using 6 - 0 Prolene, polypropylene sutures from Ethicon (Piscataway, $\mathrm{NJ}$ ). Thereafter, the rats were allowed to recuperate. The spherical volume of ecto-uterine tissue was evaluated five weeks post implantation.

The rats were randomly assigned to six test groups. Withaferin A was given at dosages of 50 , 100 , and $150 \mathrm{mg} / \mathrm{kg}$ ) to treatment group rats via oral gavage for 30 days, starting $24 \mathrm{~h}$ after implantation. Rats in the positive control received GTN at dosage of $0.5 \mathrm{mg} / \mathrm{kg} /$ day [20]. In contrast, rats in the normal control group were not induced with $E M$, and they did not receive GTN or withaferin $A$, and were given equivalent volume of saline. Separate group of rats that were implanted with ectopic tissues and they were given equivalent volume of saline in place of withaferin A or GTN served as endometriotic control. A separate group of rats treated with 150 $\mathrm{mg} / \mathrm{kg}$ withaferin A alone was not subjected to experimental endometriosis.

After five weeks, the rats were sacrificed on exposure to isoflurane anaesthesia and the endometrial tissues were excised. The ectopic spherical volume was determined using the following formula:

$V\left(\mathrm{~mm}^{3}\right)=$ length $\times$ width $\times$ height $\times 0.52 \mathrm{~mm}[21]$.

Peritoneal fluid ( $n=6$ ) was collected from each rat by rinsing the peritoneal cavity with PBS. Following centrifugation for $10 \mathrm{~min}$ at $1500 \mathrm{rpm}$, the supernatant collected was frozen at $-70^{\circ} \mathrm{C}$ until use. For immunohistochemical and histological analysis, the endometriotic tissues ( $\mathrm{n}$ = 6/ group) were processed with PBS, fixed with formalin and then embedded in paraffin. Six animals from each group were used for histology, immunohistochemistry, immunoblotting, RTPCR, and gel zymography.

\section{Measurement of ectopic tissue}

Vernier calliper was used to measure ectopic volumes of endometrial tissues. The difference between initial and post-treatment cells was calculated as change in volume $\left(\mathrm{mm}^{3}\right)$ as the change in volume $\left(\mathrm{mm}^{3}\right)$ between the volume of EM control and the volume of treatment.

\section{Immunohistochemistry (IHC) and histology}

Paraffin-embedded ectopic endometrial tissues $(n=6)$ were segmented into $4-\mu m$ slices which were treated with hematoxylin and eosin (H\&E) stain. Post staining, the tissue sections were observed and analyzed for any histological alterations using a light microscope (Leica Microsystems, Germany).

For IHC studies, the endometrial tissue sections were incubated overnight at $4{ }^{\circ} \mathrm{C}$ with primary antibodies against COX-2 and MMPs -MMP-2 and MMP-9, followed by incubation for $40 \mathrm{~min}$ with secondary antibody. The tissue sections were then rinsed well with PBS and incubated for $40 \mathrm{~min}$ with avidin-biotinylated peroxidase complex, followed by DAB (diaminobenzidine; Thermo Fischer Scientific). The positive cells were identified using image analysis and evaluation software (NIS-Elements BR, Nikon Corporation, Japan).

\section{Immunoblotting}

The endometrial tissues excised ( $n=6 /$ group) were lysed on ice using RIPA lysis buffer [1\% NP-40; $50 \mathrm{mM}$ Tris- $\mathrm{HCl}, \mathrm{pH} 7.6$, containing sodium deoxycholate $(0.5 \quad \%)$, phenylmethylsulfonyl fluoride (PMSF), SDS (0.1 $\%$ ), Aprotinin and Leupeptin (1 $\mathrm{mg} / \mathrm{L})$ ]; and the cell lysates obtained were then centrifuged. The total protein contents of the supernatants were estimated by bicinchoninic acid (BCA) assay method using BCA kit from BioRad. The cytosolic and nuclear fractions were isolated from the supernatants using NE-PER nuclear and cytoplasmic extraction kit (Pierce Biotechnology, Rockford, IL, USA) to assess the NF-kB (p65) expressions in both the fractions. Proteins $(50 \mu \mathrm{g}$ samples) from all the study groups were size fractionated electrophoretically on $10 \%$ SDSPAGE. The separated protein bands were electrotransferred onto PVDF membrane (Invitrogen). The membranes were then blocked with $5 \%$ non-fat milk and TBST buffer $(20 \mathrm{mM}$ Tris, $\mathrm{pH} 7.6$ with $137 \mathrm{mM} \mathrm{NaCl}$ and $0.1 \%$ Tween), prior to incubation overnight $\left(4^{\circ} \mathrm{C}\right.$.) with specific concentrations $(1: 1000)$ of primary antibodies. Thereafter, the membranes were then rinsed well with TBST and further incubated with secondary antibody (HRP-labelled; 1:2000) for $60 \mathrm{~min}$ at $37{ }^{\circ} \mathrm{C}$. Immunoreactive bands were visualized with chemiluminescence method (Millipore, USA) and evaluated using ChemiDoc XRS imaging system (Bio-Rad, USA). The expression levels of proteins assessed were standardized to that of the internal control ( $\beta$ actin).

\section{RT-PCR}

Total cellular RNA extracted from both ectopic and eutopic endometrial tissues (TRIzol $^{\circledR}$ reagent, Invitrogen, Carlsbad, CA, USA) was subjected to Quantitative RT-PCR to assess 
mRNA expressions of MMPs- MMP-2 and MMP9. First CDNA fragment was synthesised employing Revert Aid First Strand cDNA Synthesis Kit (Fermentas, USA), and the reactions were performed using Applied Biosystem's 7300 Real-Time PCR System (Applied Biosystems, USA) with SYBR green fluorescence. The following primers were utilized:

MMP-2 forward: 5'-CTA TTC TGC CAG CAC TTT GG-3'; reverse:5'-CAG ACT TTG GTT CTC CAA CTT-3';

MMP-9 forward: 5'-GTC TTC CCC TTC GTC TTC CT-3'; reverse: 5'-GCT GGA TGC CTT TTA TGT CG-3;

GAPDH-forward: 5'- CCG TAT CGG ACG CCT GGT TA- 3'; reverse: 5'- GGC TGT TGG TGA TAC CGA AGT A- 3'

Following amplification, the products were loaded and run on agarose gel (1\%) and the electrophoretically separated bands were visualized post staining with ethidium bromide. GAPDH expressions was regarded as standard internal control. The band intensities of the products reflecting expression levels were measured using Bio-Gel imagery apparatus (Bio-Rad, USA).

\section{Gel zymography}

The activities of MMPs -2 and 9 were assessed using gel zymography analysis. Equal volumes of proteins at $30 \mu \mathrm{g} / \mathrm{lane}$ were loaded on SDSPAGE $(10 \%)$ containing gelatin $(0.1 \%)$ and electrophoresed under non-reducing conditions. The gels were treated with Triton X-100 (2.5\%) to remove SDS, and were rinsed well with incubation buffer $(40 \mathrm{mM}$ Tris- $\mathrm{HCl}, \mathrm{pH} 7.4$, containing $0.2 \mathrm{M} \mathrm{NaCl}$ and $10 \mathrm{mM} \mathrm{CaCl}_{2}$ ) for 30 min, followed by further incubation for 18- $24 \mathrm{~h}$ at $37^{\circ} \mathrm{C}$. Thereafter, the gels were treated for $3 \mathrm{~h}$ with Coomassie blue (Coomassie brilliant blue G-250 (1 \%) in $10 \%$ acetic acid and $30 \%$ methanol), and de-stained in acetic acid (7\%) and methanol (40\%) till clear bands indicating gelatinolytic zones were noticed against a black background. Total activity of MMPs was determined with densitometry by means of an ATTO Densitograph Software Library Lane Analyzer (Atto Instruments, Rockville, USA).

\section{Determination of inflammatory mediators with ELISA}

The concentrations of interleukins- IL-1 $\beta$ and IL6 in the peritoneal fluids were evaluated with ELISA using commercial kits in line with the instructions specified by the manufacturer (Biolegend, San Diego, CA, USA). The levels were measured with an automatic plate reader (SpectraMax 190), and further analysis was done with SoftMax Pro software (Molecular Devices, Sunnyvale CA, USA).

\section{Determination of nitric oxide (NO)}

NO level in the peritoneal fluid was measured by nitrite/nitrate conversion method. The assay protocol utilizes nitrate reductase, the enzyme that converts nitrate to nitrite. The Griess reagent employed converts nitrite in the sample to a deep purple azo compound. In this study, the intensity of absorbance of the azo compound was measured at $540 \mathrm{~nm}$ in an ELISA reader. Absorbance of the chromophore reflected the concentration of nitrite.

\section{In vitro assays}

Ectopic endometrial tissues isolated, were pulverized and incubated in Hank's balanced salt solution containing deoxyribonuclease (1500 $\mathrm{U} / \mathrm{mg}$ ) and HEPES for an hour at $37^{\circ} \mathrm{C}$, with agitation and then centrifuged at $4{ }^{\circ} \mathrm{C}$. The cell pellets were washed and suspended in Ham F12: DMEM (1:1 v:v) that contained fetal bovine serum (FBS; $10 \%$ ) and penicillin or streptomycin (1\%). The cells were strained through a $40-\mu \mathrm{m}$ cell filter (Falcon) and plated into cell culture flasks (BD Biosciences, San Jose, CA, USA). Cells at $3-5$ passages were used for analysis.

For measurement of cell viability, the cells were seeded at of $0.5 \times 10^{6}$ cell density/well in a 96well plates and incubated at $37^{\circ} \mathrm{C}$ for $24 \mathrm{~h}$. The cells were exposed to various concentrations of withaferin $\mathrm{A}(20-100 \mu \mathrm{M})$ for $24 \mathrm{~h}$, prior to treatment with 3-(4,5-dimethylthiazol-2-yl)-2,5diphenyltetrazolium bromide (MTT). The resultant purple-colored formazan crystals formed were dissolved in DMSO, and the absorbance of the solution was read spectrophotometrically at $570 \mathrm{~nm}$ (Spectra Max 190, Molecular Devices, Sunnyvale, CA, USA).

\section{Statistical analysis of data}

The data obtained from different study groups were evaluated for statistical significance at $p<$ 0.05 . Group comparisons were carried out with Statistical Package for the Social Sciences (SPSS software; version 21.0, IBM Corporation, USA). The values obtained following analysis were statistically analyzed by One-way analysis of variance (ANOVA), that was followed by Duncan's Multiple Range Test (DMRT). 


\section{RESULTS}

\section{Withaferin A inhibited the growth of ectopic} endometrial tissues

The impact of withaferin A on the development of endometrial ectopic tissue was measured. The quantity of ectopic endometrial tissue in EM control group was increased, relative to the regular control group (Table 1). Interestingly, 30day treatment with withaferin $A$ at tested dosages of 50,100 and $150 \mathrm{mg} / \mathrm{kg}$ caused marked reductions in the spherical volume of ectopic tissues in a dose-dependently, with the dose of $150 \mathrm{mg} / \mathrm{kg}$ exerting maximal protective effects. The volume of ectopic tissues was reduced to $11.57 \pm 1.01 \mathrm{~mm}^{3}$ in animals that were treated with the withaferin $A$ at $150 \mathrm{mg} / \mathrm{kg}$ dosage. In GTN-treated rats, substantial ( $p<$ 0.05 ) reduction in the volume of ectopic tissues was noticed, when compared with EM control. Histopathological examination revealed markedly decreased atrophy and substantial regression of endometriotic lesions following withaferin A treatment (Figure 1). Furthermore, in vitro studies on ectopic endometrial tissues revealed that withaferin $A(p<0.05)$ markedly decreased cell viability, where the percentage of viable cells was reduced to 51 on treatment with $100 \mu \mathrm{M}$ withaferin (Figure 2).

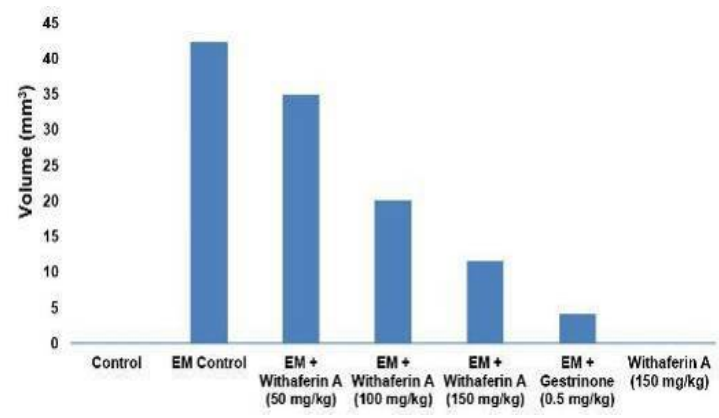

Figure 1: Effects of withaferin $A$ on lesion volume. Mean values are presented $(n=6)$. Withaferin $A$ administration dose-dependently reduced endometrial lesion volume

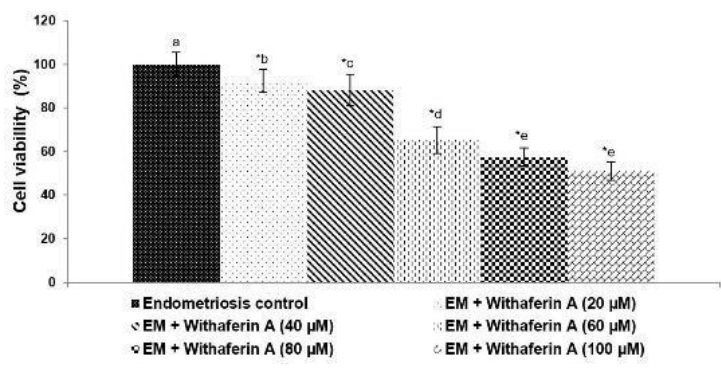

Figure 2: Effect of withaferin A on viability of cells in the ectopic endometrial tissues. Results are presented as mean $\pm \mathrm{SD} ; \mathrm{n}=6$. ${ }^{*} p<0.05$ vs normal control; $\# p<$ 0.05 , vs endometriotic control; a-e denotes means from the study groups differing at $p<0.05$

\begin{tabular}{|c|c|}
\hline $\begin{array}{l}\text { Withaferin A } \\
\text { metalloproteinases } \\
\text { endometrial tissues }\end{array}$ & $\begin{array}{l}\text { inhibited } \\
\text { in the }\end{array}$ \\
\hline
\end{tabular}

Expression levels of MMPs- 2 and -9 at protein and mRNA levels were markedly $(p<0.05)$ enhanced in ectopic endometrial tissues of EM control rats, when compared to normal control (Figures $3 \mathrm{~A}$ and $\mathrm{B}$ ). The MMP-2 mRNA and MMP-9 mRNA concentrations increased to 2.1 and 1.89 folds, respectively in the EM control rats. In eutopic endometrial tissues, negligible changes in expressions were noticed amongst the EM control, treatment and normal control groups. However, administration of withaferin A for 30 days following experimental induction of EM markedly reduced MMP levels in the ectopic endometrial tissues, while MMP expression in eutopic endometrium remained almost unchanged. The protein expressions of MMP-2 and -9 as assessed by immunoblotting were reduced in the ectopic endometrial tissues following withaferin $A$ administration (Figures 3 $C$ and D). Immunohistochemical analysis also revealed similar reductions in the in situ expressions of MMP-2 and MMP-9 in ectopic tissues of EM, withaferin A-treated rats, relative to EM control (Figure 4).

Table 1: Withaferin A reduced the volume of endometriotic lesions

\begin{tabular}{lcc}
\hline Experimental group & Volume $\left(\mathbf{m m}^{3}\right)$ & Change in volume $\left.\mathbf{~ ( m m ~}^{3}\right)$ \\
\hline Control & - & - \\
Endometriosis control & $42.3 \pm 1.76$ & - \\
EM + Withaferin A $(50 \mathrm{mg} / \mathrm{kg})$ & $34.9 \pm 1.88 \mathrm{ab}$ & $7.5 \pm 0.60$ \\
EM + Withaferin A $(100 \mathrm{mg} / \mathrm{kg})$ & $20.15 \pm 1.72 \mathrm{ac}$ & $19.78 \pm 0.19$ \\
EM + Withaferin A $(150 \mathrm{mg} / \mathrm{kg})$ & $11.57 \pm 1.01 \mathrm{ac}$ & $27.02 \pm 1.34$ \\
EM + Gestrinone $(0.5 \mathrm{mg} / \mathrm{kg})$ & $4.11 \pm 0.54$ ad & $37.43 \pm 2.07$ \\
Withaferin A & - & -
\end{tabular}

Volume is presented as mean $\pm S D ; n=6$. ${ }^{a} p<0.05$, vs endometriosis control, ${ }^{b-d}$ are means of different study groups differing at $p<0.05$. Withaferin A treatment significantly decreased the volume of endometriotic lesions $(p$ $<0.05)$ 
Consistent with mRNA expressions of MMPs-2 and MMP-9, protein levels were negligibly changed in eutopic endometrium of animals treated with withaferin $A$, relative to standard control and eutopic control. Non-EM rats treated with withaferin A alone had MMP levels almost similar to normal control levels (Figures $3 \mathrm{~A}$ and D). Gel zymography analysis indicated significantly $(p<0.05)$ enhanced MMPs-2 and MMP-9 activities in the ectopic endometrium of EM control rats. Withaferin A administration led to substantial decreases in the activities of the MMPs in line with the protein expression levels (Figures $4 \mathrm{C}$ and $\mathrm{D}$ ), indicating altered expressions in the ectopic endometrial tissues.

A

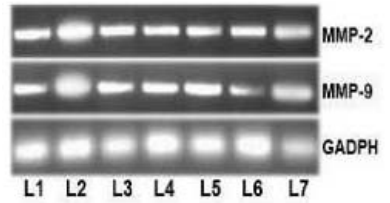

B

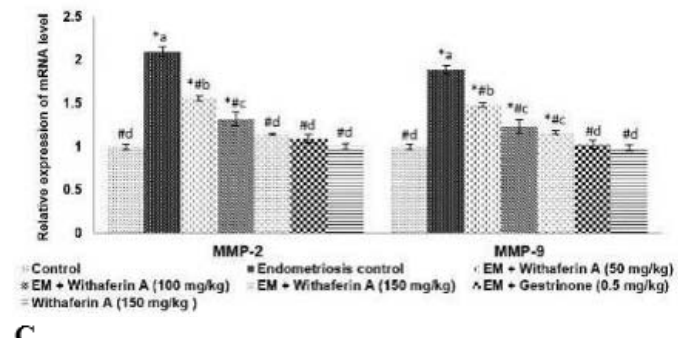

C

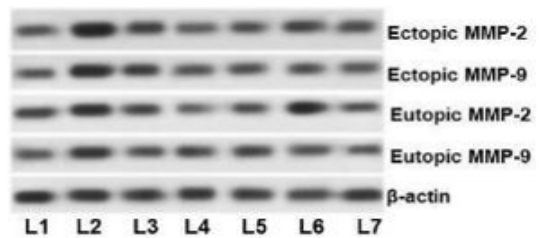

D

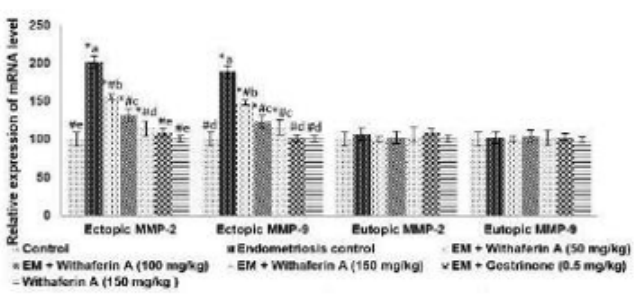

Figure 3: Effects of withaferin $A$ on expressions of MMP-2 and MMP-9. A \& B: Relative expressions of mRNA levels. (C) Representative immunoblots. (D) Protein expressions relative to control expressions set at $100 \%$. Values are presented as mean $\pm \operatorname{SD}(n=6)$. ${ }^{*} p<0.05$, vs normal control; $\# p<0.05$, vs endometriotic control; a-e denote means of treatment groups differing at $p<0.05$
A

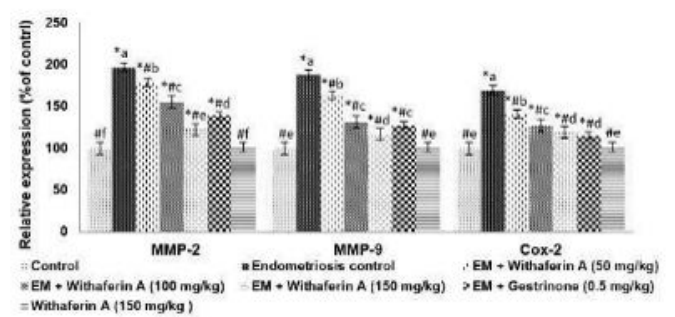

B

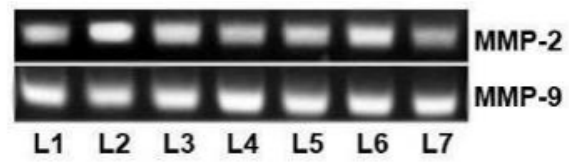

C

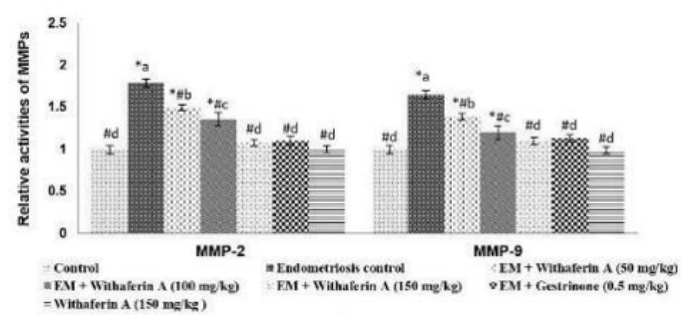

Figure 4: Effect of withaferin A on MMP-2, MMP-9 and COX-2 expressions. A. Immunohistochemical analysis- Protein expressions relative to control $(100 \%)$. B and C: Gel zymography - Activities of MMP2 and MMP- 9. Values are presented as mean $\pm S D$, $(\mathrm{n}=6) .{ }^{*} p<0.05$, vs normal control; $\# p<0.05$, vs endometriotic control; a-d denote mean values of the study groups differing at $p<0.05$. The data analyzed by one-way ANOVA and DMRT. L1 = Control; L2 = endometriosis control; L3 $=E M+$ withaferin A (50 $\mathrm{mg} / \mathrm{kg}) ; \mathrm{L} 4=\mathrm{EM}+$ withaferin A $(100 \mathrm{mg} / \mathrm{kg}) ; \mathrm{L} 5=\mathrm{EM}$ + withaferin A (150 mg/kg); L6 = EM + gestrinone $(0.5$ $\mathrm{mg} / \mathrm{kg}) ; \mathrm{L} 7=$ withaferin $\mathrm{A}(150 \mathrm{mg} / \mathrm{kg})$

\section{Withaferin A reduced inflammatory responses}

Results from immunohistochemical analysis and western blot analysis (Figure 5) illustrated significantly enhanced $(p<0.05)$ expressions, relative to normal control. The NF-KB signaling was activated in ectopic tissues, as was evident in marked increases in NF-KB (p65) in the nucleus along with substantially reduced NF-kB (p65) in the cytosol $(p<0.05)$. Furthermore, the expression levels of activated forms of inhibitor kinases of NF-KB signaling were remarkably upregulated in endometriotic lesions, along with enhanced TNF- $\alpha$ (Figure 6). Withaferin $A$ at specified dosages of 50,100 and $150 \mathrm{mg}$ administered for 30 days caused a substantial down-regulation of NF-KB (p65) in the nuclear fraction and marked $(p<0.05)$ decreases in 
activated form of kinases ( $\mathrm{p}-\mathrm{IKK \alpha}, \mathrm{p}-\mathrm{IKK} \beta$, and plkBa), leading to suppression of the NF-KB pathway inhibition. Moreover, TNF-a expression was reduced by withaferin $A$. Consistent with protein expressions, proinflammatory cytokines IL-1 $\beta$ and IL-6, and NO were noticed to be substantially $(p<0.05)$ high in the peritoneal fluid of EM rats, relative to non-EM control group rats. Treatment with GTN resulted in appreciable decreases in IL-1 $1 \beta$ and IL- 6 levels. Withaferin A dose-dependently, reduced IL-6 and $\mathrm{IL}-1 \beta$, with $150 \mathrm{mg} / \mathrm{kg}$ dose being more effective compared to 50 and $100 \mathrm{mg} / \mathrm{kg}$.

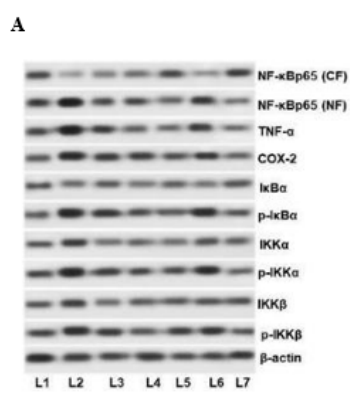

B

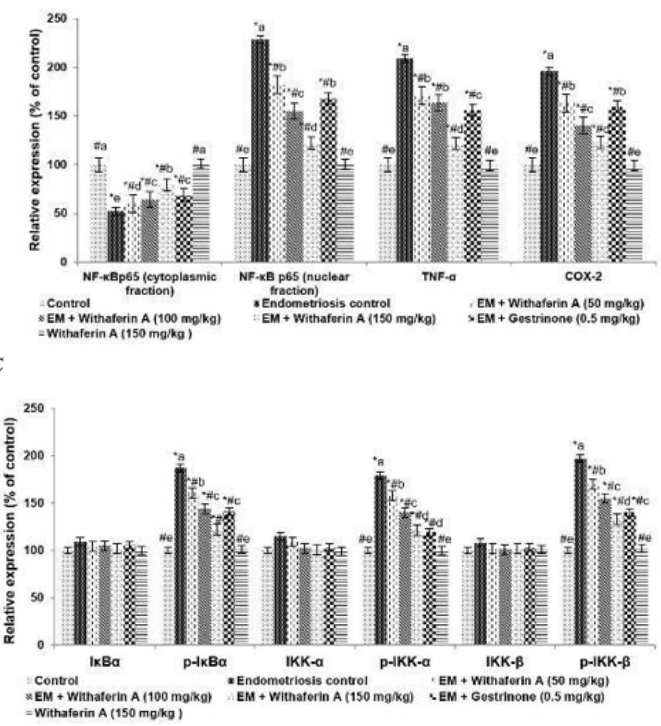

Figure 5: Effect of withaferin-A on NF-kB signaling. A: Representative immunoblots. B \& C: Protein expressions relative to control set at $100 \%$; Expression levels are presented as mean \pm SD ( $n=$ 6 ); $p<0.05$; ${ }^{*} p<0.05$, vs normal control; $\# p<0.05$, vs endometriotic control; a - e denote means from the study groups differing with each other at $p<0.05$. The data analyzed by one-way ANOVA and DMRT. L1 = Control; $\mathrm{L} 2=$ endometriosis control; $\mathrm{L} 3=\mathrm{EM}+$ withaferin A (50 mg/kg); L4 = EM + withaferin A (100 $\mathrm{mg} / \mathrm{kg}) ; \mathrm{L} 5=\mathrm{EM}+$ withaferin A $(150 \mathrm{mg} / \mathrm{kg}) ; \mathrm{L} 6=\mathrm{EM}$ + gestrinone $(0.5 \mathrm{mg} / \mathrm{kg}) ; \mathrm{L} 7=$ withaferin $\mathrm{A}(150$ $\mathrm{mg} / \mathrm{kg}$ )
A
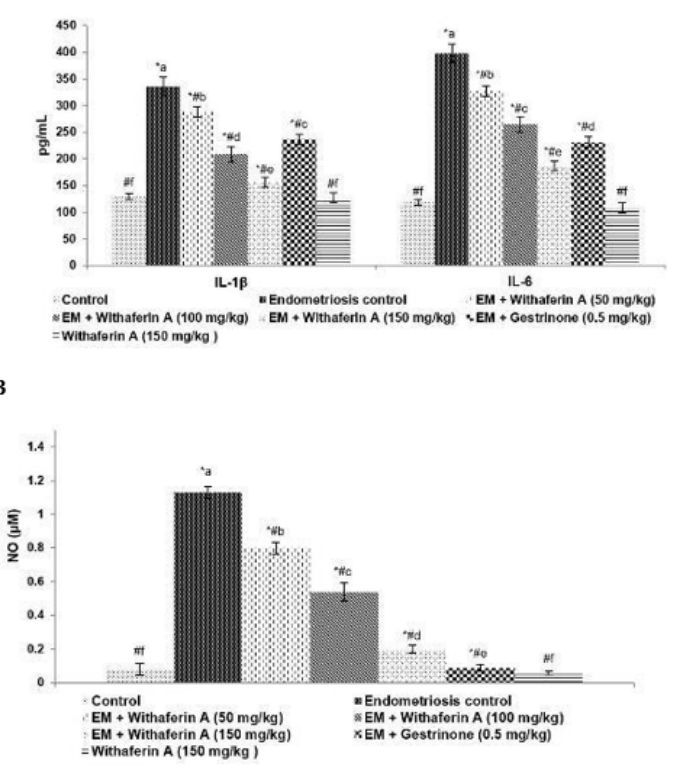

Figure 6: Effect of withaferin $A$ on the levels of inflammatory mediators. A: Levels of cytokines. B: NO levels. Values are presented as mean $\pm \mathrm{SD} ; \mathrm{n}=6$. ${ }^{*} p$ $<0.05$, vs control; $\# p<0.05$, vs endometriotic control; a - $\mathrm{f}$ denotes means from study groups differing at $p<$ 0.05 . The data analysed by one-way ANOVA and DMRT

\section{DISCUSSION}

Endometriosis, a common clinical condition with complex etiology, affects women in their reproductive age. EM is characterized by growth of functional endometrial tissue outer the uterus [2]. The molecular events underlying the pathogenesis of EM are yet to be clearly understood. The current treatment modalities for EM (surgery and hormonal therapy) are associated with side effects as hepatic injury, weight gain, altered lipid metabolism, and osteoporosis [22]. Furthermore, these treatments result in high frequency of relapse. Thus, there is need for novel therapeutic strategies with higher efficiencies and negligible side effects.

Animal models are widely used to investigate EM with respect to disease progression, pathology, and novel bioactive therapeutic compounds. Recent studies have focused on exploring the efficacy of plant-derived compounds in the treatment of EM. In the present research, the effect of withaferin $A$ on EM rats was investigated. EM was induced in rats via ectopic auto-transplantation of uterine tissues [19].

In this study, Withaferin A supplementation for 30 days significantly reduced the growth of the ectopic endometrial tissues. Histopathological 
results showed that withaferin $A$ induced substantial reduction in the progression of atrophy and lesions. These observations suggest the efficacy of withaferin A. Similar results have been reported in studies with plant-derived compounds such as resveratrol [23].

Metalloproteinases (MMPs) are zinc-dependent proteases involved in the degradation and renewal of several types of tissues. Studies have reported significantly raised expressions of MMPs in ectopic endometrium, suggesting association between MMPs and EM. It has been demonstrated that MMP-2 and MMP-9 are implicated in the development of EM $[8,9]$. Here, we noticed markedly high expressions of MMPs 2 and 9 at transcriptional and translational levels (mRNA and protein levels) in the ectopic endometrial tissues, which are in agreement with previous reports [24].

While enhanced expressions of MMP were seen in the ectopic endometrial tissues, their levels remained virtually unchanged in the eutopic endometrium. The severity of endometriosis is associated with the degree of MMP-2 and MMP9 expressions. The observed rise in MMPs -2 and -9 were restricted to ectopic tissues. This indicates the effects of MMPs on the local microenvironment and progression of the disease. However, withaferin A significantly downregulated mRNA and protein expressions of MMP-2 and- 9 in the ectopic endometrium, indicating the efficacy of withaferin in modulating the local microenvironment, thereby suppressing EM. Studies have shown that inhibition of MMPs suppresses the development of endometriotic lesions [9]. Thus, the withaferin A-mediated inhibition of MMP-2 and MMP-9 could have aided to the observed restoration of histology of ectopic endometrial tissues.

Inflammatory processes are implicated in endometriosis. Endometriosis-associated inflammatory responses and neo-vascularisation process are mediated by macrophages of the peritoneal fluid [15]. The macrophage-derived cytokines exert significant regulatory effect on cell proliferation, activation, and morphogenesis in the progression of EM [15]. Increased cytokine levels have been reported in $\operatorname{EM}[10,11]$. Constitutive activity of NF-KB signals have been reported in endometriotic tumors and pelvic macrophages [12]. This demonstrates the association between inflammatory pathways and EM.

In the present study, significant initiation of NF$\mathrm{KB}$ signaling was seen after experimental initiation of EM, as reflected in raised expression level of p65NF-kB in the nucleus and enhanced activation of the signal through phosphorylation of $\mathrm{IKK} \alpha, \mathrm{IKK} \beta$, and $\mathrm{IKBa}$, the key regulatory kinases. Under normal physiological conditions, in the absence of a stimulus, NF-KB is found in the cytosol, bound to inhibitor proteins (IkB family of proteins). However, following a stimulus, NF-kB gets activated and NF-kB p65 translocates to the nucleus, resulting in expressions of downstream target genes that code for proteins of the inflammatory pathways.

In this study, markedly raised COX-2, TNF- $\alpha$, IL$1 \beta$ and IL-6 observed on EM induction demonstrate increased NF-kB signal activation and thus, enhanced inflammatory responses in EM. The level of TNF- $\alpha$ in peritoneal fluids serves as a biomarker of EM.

The results obtained indicates the crucial influence of inflammatory mediators in the progression of EM. Inhibition of inflammatory cascades through down-regulation of NF-kBmediated signaling is crucial in EM therapy. Interestingly, marked suppression of NF-KB signaling and reductions in NO, TNF- $\alpha, \mathrm{COX}-2$, IL-1 $\beta$ and IL-6 strikingly establish the antiinflammatory efficiency of withaferin $A$. The withaferin A-mediated down-regulation of NF-KBinduced inflammatory responses, along with decreased MMP-2 and MMP-9 levels, may be responsible for the decreases in proliferation of lesions, as well as inhibition of the microenvironment that favors EM.

The results of the study are comparable to that of earlier reports on the effects of phytochemicals in experimental EM. Zhou et al [25] reported that extracts of Salvia miltiorrhiza Bunge exerted potent anti-inflammatory effects in experimental model of EM. Euterpe oleracea extracts significantly inhibited the proliferation of endometriotic lesions and decreased MMP-9, COX-2 expressions and cytokines in an experimental model of EM. These results demonstrate the benefits of the use of phytochemicals in endometriosis, and they are consistent with the findings of the present research. Thus, withaferin $A$ is a prospective candidate drug for the treatment of endometriosis.

\section{CONCLUSION}

These findings demonstrate the potent antiinflammatory efficacy of withaferin $A$ and its possible use in the therapy of EM. Nevertheless, there is need for further investigations to understand the molecular mechanisms 
associated with the anti-EM effects of withaferin A.

\section{DECLARATIONS}

\section{Conflict of interest}

No conflict of interest is associated with this work.

\section{Contribution of authors}

We declare that this research work was executed by author(s) - Wang Dan, Jiang Yiling, Li Chun, Fan Jing, Wang Huimin and Yang Xiaoxin and all liabilities pertaining to claims relating to the content of this article will be borne by the authors. Wang Dan and Jiang Yiling contributed to this work equally.Yang Xiaoxin, Li Chun, Fan Jing and Wang Huimin contributed in the experimental works and in statistical study and all authors had contributed in all aspects of this research.

\section{Open Access}

This is an Open Access article that uses a funding model which does not charge readers or their institutions for access and distributed under the terms of the Creative Commons Attribution License (http://creativecommons.org/licenses/by/ 4.0) and the Budapest Open Access Initiative (http://www.budapestopenaccessinitiative.org/rea d), which permit unrestricted use, distribution, and reproduction in any medium, provided the original work is properly credited.

\section{REFERENCES}

1. Eskenazi B, Warner ML. Epidemiology of endometriosis. Obstet Gynecol Clin North Am 1997; 24: 235-258.

2. Vinatier $D$, Orazi G, Cosson M, Dufour P. Theories of endometriosis. Eur J Obstet Gynecol Reprod Biol 2001; 96: 21-34.

3. van Langendonckt A, Casanas-Roux F, Donnez J. Oxidative stress and peritoneal endometriosis. Fertil Steril 2002; 77: 861-870.

4. Ruhland B, Agic A, Krampe J, Diedrich K, Hornung D. Innovations in conservative endometriosis treatment: an updated review. Minerva Ginecol 2011; 63: 247-259.

5. Wang N, Liu B, Liang L, Wu Y, Xie H, Huang J, Guo X, Tan J, Zhan X, Liu $Y$, et al. Antiangiogenesis therapy of endometriosis using PAMAM as a gene vector in a noninvasive animal model. Biomed Res Int 2014; 2014: 546479.

6. Guo SW, Olive DL. Two unsuccessful clinical trials on endometriosis and a few lessons learned. Gynecol Obstet Invest 2007; 64: 24-35.
7. Brinckerhoff CE, Matrisian LM. Matrix metalloproteinases: a tail of a frog that became a prince. Nat Rev Mol Cell Biol 2002; 3: 207-214.

8. Osteen KG, Yeaman GR, Bruner-Tran KL. Matrix metalloproteinases and endometriosis. Semin Reprod Med 2003; 21: 155-164.

9. Bruner KL, Matrisian LM, Rodgers WH, Gorstein F, Osteen KG. Suppression of matrix metalloproteinases inhibits establishment of ectopic lesions by human endometrium in nude mice. J Clin Invest 1997; 99: 2851-2857.

10. Harada $T$, Iwabe $T$, Terakawa N. Role of cytokines in endometriosis. Fertil Steril 2001; 76: 1-10.

11. Sidell N, Han SW, Parthasarathy S. Regulation and modulation of abnormal immune responses in endometriosis. Ann NYAcad Sci 2002; 955: 159-173.

12. Lousse JC, Defrère S, Van Langendonckt A, Gras J, González-Ramos R, Colette S, Donnez J. Iron storage is significantly increased in peritoneal macrophages of endometriosis patients and correlates with iron overload in peritoneal fluid. Fertil Steril 2009; 91: 1668-1675.

13. Chishima F, Hayakawa S, Sugita K, Kinukawa N, Aleemuzzaman S, Nemoto N, Yamamoto T, Honda $M$. Increased expression of cyclooxygenase-2 in local lesions of endometriosis patients. Am J Reprod Immunol 2002; 48: 50-56.

14. Vyas AR, Singh SV. Molecular targets and mechanisms of cancer prevention and treatment by withaferin- $A$, a naturally occurring steroidal lactone. AAPS J 2014; 16 : 1-10.

15. Bargagna-Mohan P, Hamza A, Kim YE, Khuan-AbbyHo $Y$, Mor-Vaknin N, Wendschlag N, Liu J, Evans RM, Markovitz DM, Zhan CG, et al. The tumor inhibitor and antiangiogenic agent withaferin $A$ targets the intermediate filament protein vimentin. Chem Biol 2007; 14: 623-634.

16. Okamoto S, Tsujioka $T$, Suemori $S$, Kida J, Kondo $T$, Tohyama Y, Tohyama K. Withaferin A suppresses the growth of myelodysplasia and leukemia cell lines by inhibiting cell cycle progression. Cancer Sci 2016; 107: 1302-1314.

17. Lee J, Liu J, Feng X, Salazar Hernández MA, Mucka $P$, Ibi D, Choi JW, Ozcan U. Withaferin $A$ is a leptin sensitizer with strong anti-diabetic properties in mice. Nature Med 2016; 22: 1023-1032.

18. Garber JC. Committee for the update of the guide for the care and use of laboratory animals. In: Guide for the care and use of laboratory animals. 8th ed. National Academy of Sciences, USA; 2011.

19. Vernon MW, Wilson EA. Studies on the surgical induction of endometriosis in the rat. Fertil Steril 1985; 44: 684694.

20. Tang $Q$, Shang $F$, Wang $X$, Yang $Y$, Chen $G$, Chen $Y$, Zhang $J, X u X$. Combination use of ferulic acid, ligustrazine and tetrahydropalmatine inhibits the growth of ectopic endometrial tissue: a multi-target therapy for endometriosis rats. J Ethnopharmacol 2014; 151: 12181225.

Trop J Pharm Res, February 2021; 20(2): 247 
21. Yildirim G, Attar R, Ozkan F, Kumbak B, Ficicioglu C, Yesildaglar $N$. The effects of letrozole and melatonin on surgically induced endometriosis in a rat model: a preliminary study. Fertil Steril 2010; 93: 1787-1792.

22. Chen ZZ, Gong X. Effect of Hua Yu Xiao Zheng decoction on the expression levels of vascular endothelial growth factor and angiopoietin-2 in rats with endometriosis. Exp Ther Med 2017; 6: 5743-5750.

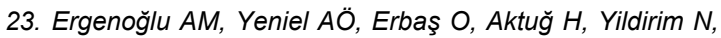
Ulukuş $M$, Taskiran D. Regression of endometrial implants by resveratrol in an experimentally induced endometriosis model in rats. Reprod Sci 2013; 20: 1230 1236.

24. Jiao L, Qi X, Lu G, Zhang Q, Zhang C, Gao J. Effect of traditional Chinese medicine (Xiaochaihu Tang) on the expression of MMP-2 and MMP-9 in rats with endometriosis. Exp Ther Med 2013; 6: 1385-1389.

25. Zhou R, He LF, Li YJ, Shen Y, Chao RB, Du JR. Cardioprotective effect of water and ethanol extract of Salvia miltiorrhiza in an experimental model of myocardial infarction. J Ethnopharmacol 2012; 139: 440-446. 